\title{
Una conversación salvaje para la comprensión de la pandemia por COVID-19
}

Conversación entre Ailton Krenak y Marcelo Gleiser.

Selvagem, ciclo de estudos sobre a vida, Dantes Editora (Org.).

Transmitido en vivo el 17 de abril de 2020,

recuperado de: https://www.youtube.com/watch?v=xeAI7GDOefg\&t=22s

Hortensia Castro

Universidad de Buenos Aires. Facultad de Filosofía y Letras. Departamento e Instituto de Geografía "Romualdo Ardissone". Buenos Aires, Argentina

\section{La parte y el todo}

El objeto de esta reseña es un encuentro entre Ailton Krenak, una de las principales voces del saber indígena en Brasil, y Marcelo Gleiser, un importante físico teórico de origen brasileño, para compartir puntos de vista acerca de nuestro lugar como humanos en el planeta $y$, a través de ellos, desarrollar una serie de reflexiones sobre la actual pandemia por COVID-19.

La conversación entre ambos transcurre en el marco de Selvagem, ciclo de estudos sobre a vida, un espacio que propicia el diálogo de saberes a través del encuentro entre científicos, filósofos, líderes indígenas, economistas y escritores, entre otros. El ciclo es organizado desde el año 2019 por la Editorial Dantes de Brasil e incluye una serie de reuniones mediadas por Ailton Krenak, así como la publicación y la difusión de libros, notas y videos. Este año 2020 las conversaciones se retomaron de modo virtual con el encuentro que aquí se reseña, trasmitido en vivo el 17 de abril de 2020.

El título del encuentro, Conversa selvagem (conversación salvaje), da cuenta del estilo del diálogo: abierto, diverso y, sobre todo, provocador, tanto entre los expositores como para los asistentes; quizás también ese título sirva para recordarnos, figurativamente, el "paseo por el lado salvaje" (walk on the wild side) que hemos estado transitando hasta ahora y que se expresaría en la actual pandemia.

\section{Diálogo de saberes y narrativas}

Marcelo Gleiser es profesor de física y astronomía en el Dartmouth College (New Hampshire), donde además dirige el Instituto para el Compromiso Interdisciplinario. Es cofundador de un blog sobre ciencia y cultura de la radio pública de ese país (13.7 Cosmos \& Culture). Entre sus libros se encuentran $A$ Tear at the Edge of Creation (Simon \& Schuster, 2010), The Island of Knowledge: The Limits of Science and The Search for Meaning (Perseus Books, 2014) y The Simple Beauty of the Unexpected (ForeEdge, 2016).

Ailton Alves Krenak Lacerda vive en la aldea Krenak, en las márgenes del río Doce, en el estado de Minas Gerais. En la década de 1980 contribuyó a la creación de la Unión de Naciones Indígenas y participó de la Asamblea Nacional que redactó la Constitución brasileña de 1988. Es periodista y escritor; entre sus textos se destaca el libro Ideias para Adiar o Fim do Mundo (Companhia das Letras, 2019).

La conversación entre ambos se organiza a partir de dos interrogantes cruzados: ¿por qué para las culturas indígenas la naturaleza es sagrada y qué podemos aprender de eso? (le pregunta Marcelo a Ailton), y ¿cómo llegamos a la idea de que hombre y naturaleza están separados? (interpela Ailton a Marcelo). A partir de esas preguntas se hilvana un diálogo que expone diferentes narrativas sobre la relación entre humanos y no humanos, así como sobre la comprensión del lugar de la naturaleza en 
Una conversación salvaje para la comprensión de la pandemia por COVID-19 HORTENSIA CASTRO

ellas, donde se hacen evidentes las disidencias y los puntos de encuentro entre ambos.

El relato de Marcelo Gleiser se estructura en torno a ciertos hitos para la comprensión del proceso de separación entre hombre y naturaleza. Parte de una línea-base: un pasado de cazadores-recolectores con una relación de fuerte dependencia hacia la naturaleza (necesitaban de ella para su propia supervivencia), que derivaría en una actitud de reverencia y miedo. El segundo hito es situado en el siglo VI a.C., cuando los pre-socráticos inician la conformación de otra relación hombre/ naturaleza: ya no de sacralización sino de explicación de los mecanismos que operan en la naturaleza; se estaban estableciendo, así, las bases de lo que posteriormente sería la ciencia mecánica moderna. Precisamente reconoce a los siglos XVI a XVII como un tiempo clave para la operación de separación entre hombre y naturaleza, con la idea de ésta como una máquina, cuyas leyes pueden y deben ser descifradas por el hombre (científico) para poder controlarla. Se establece, de esa manera, no sólo una disociación sino, sobre todo, una jerarquización: la de superioridad humana sobre la naturaleza. Según Marcelo, a partir de ese momento la concentración poblacional y la necesidad de alimentos y energía, "bajo una búsqueda constante de lucro", llevaron a la explotación desenfrenada de la naturaleza y a una pérdida de la relación de nosotros, como humanos, con ella. Expresa, de ese modo, una narrativa ecológica, en la que la ciencia moderna tiene un rol clave en la conformación de patrones productivistas y consumistas y en la dicotomía hombre-naturaleza que los sustenta.

La narrativa que ofrece Ailton Krenak, en cambio, no sigue un tiempo lineal de orden secuencial; incluso caracteriza como un engaño la idea del "tiempo como flecha” presupuesta en el relato de Marcelo, fundamentalmente por su efecto prospectivo. Asimismo, en su narrativa no opera la distinción humano-naturaleza $y$, por tanto, tampoco el poder del primero sobre la segunda. "Todos son parientes nuestros", dice, y en esa frase resume la idea de origen común y cohabitación. Se posiciona, así, en la tradición de varios pueblos originarios de América y de otras regiones, entendiendo a los humanos como producto de la transformación de otros seres ("todos fuimos alguna otra cosa antes de ser seres humanos" y llevamos "la memoria de sí antes de ser configurados como humanos"). Incluso prefiere hablar de Cosmos, más que de planeta Tierra, justamente para comprender el tránsito entre aquello que está en la Tierra y lo que se encuentra fuera de ella. También plantea que la idea misma de humanidad es una ficción, porque presupone una unidad constituida a lo largo de miles de años ("una unánime-humanidad") cuando, en realidad, estamos constituidos por muchas partes, constelaciones de gentes con diferentes memorias y existencias. En su relato, además, la selva como ámbito de alta biodiversidad tiene un lugar central, tanto para destacarla como un "vasto organismo inteligente" $(y$, a través de ella, enfatizar su interpretación como fuerza vital, superior a cada uno de nosotros) como para advertir sobre su riesgo de extinción y la necesidad de protegerla efectivamente, particularmente frente a la ineficacia de los programas contra la deforestación de los últimos cuarenta años.

Ese planteo del "origen común" (también retomado y afirmado por Marcelo en clave científica al mencionar que todas las formas de vida parten de una bacteria común o que compartimos genes con otras especies) adquiere un sentido clave, correspondido, en este diálogo de saberes: los humanos y no humanos somos una unidad, existimos junto con el otro, aquello que acontece a unos repercute en los otros. ¿Podremos, entonces, tener un "futuro común"? El actual contexto de pandemia se hace ineludible para abordar esa pregunta a lo largo de la conversación, tal como veremos a continuación.

\section{Sobre virus, parásitos y plagas}

La pandemia por COVID-19 hace evidente, de manera drástica y crítica, que "la gente no está realmente separada de la naturaleza", dice Marcelo. Y frente a esa constatación ambos eligen colocar el foco de atención sobre los comportamientos humanos que llevaron a esta crisis actual.

Para Ailton el "desvío" se produjo cuando los humanos descubrieron que se podían apropiar de una técnica y operar de modo activo sobre los organismos de la Tierra. Incluso denomina a los diferentes artefactos técnicos como "juguetes", es decir, objetos que nos entretienen mientras se 
destruye nuestro vínculo con la naturaleza y el planeta mismo, e instala otra provocación al preguntar "¿por qué celebrar ciertos juguetes, como Internet, si el planeta es un organismo mucho mayor, más sabio, que puede desconectarnos" (como expresa la pandemia)? En ese sentido, concluye, "gran parte de la historia de la humanidad es una vergüenza".

Marcelo, si bien difiere de la lectura de Ailton con respecto a las innovaciones tecnológicas al destacar los beneficios de la ciencia en el mejoramiento de la calidad de vida del ser humano, coincide en que la crisis actual es resultado de que los humanos ya no son una especie que convive con el planeta sino que lo explota de "forma parásita"; "somos la peste del planeta Tierra", insiste (una idea que Ailton refuerza al afirmar "la plaga somos nosotros, no la COVID"). En ese sentido, concluye Marcelo en clave evolutiva, "[los humanos] fuimos los últimos en entrar a la fiesta y si no la cuidamos seremos los primeros en salir".

Ambos coinciden en que esta crisis también permite $y$, sobre todo, demanda aprendizajes y propuestas. Para Marcelo se trata de "mirar para adentro", evaluar los comportamientos propios (cómo cada uno come, usa la energía, etc.) y reentrenarse para ver la cadena de relaciones con la naturaleza (un desafío mayor, advierte, en las grandes ciudades donde las transformaciones ambientales no se sienten con tanta fuerza, así como tampoco los efectos de los cambios individuales). También destaca la importancia de los liderazgos para instalar y esparcir, desde cada comunidad, la idea de la necesidad de "preservación planetaria como nuevo virus".

Ailton, asimismo, insiste en la importancia de parar, de detenerse: "si fuimos capaces de acatar el confinamiento en nuestras casas y el distanciamiento social, entonces ¿no seremos capaces de oír la orden de 'paren de depredar el planeta'?" Ahora bien, el valor trascendente de ríos, bosques, selvas, aires, etc. amerita, dice, un enunciado acorde: no debe ser "Usted debe parar" sino "nosotros precisamos parar". Y convierte esa premisa en un acto performativo: instó en el encuentro a dejar de hablar durante un minuto para poder pensar y reflexionar, expresando con la necesidad de ese gesto la aceleración y el consumismo contemporáneos. Incluso Ailton deriva la "importancia de parar" hacia un tema sensible, complejo y controversial: el crecimiento poblacional, al señalar que "somos una especie que crece desordenadamente" y que "la moral moderna impide pensar cuántos podemos seguir habitando en el planeta". Al respecto busca salirse de la idea fascista de control poblacional para advertir que la fantasía prometida por "la economía y la ciencia, [de que] toda la población tendrá comida y morirá cada vez más tarde", impide que la gente acepte su ciclo no solo con la naturaleza sino con respecto a su propia vida.

$\mathrm{Si}$, como señala Marcelo, "todo en la naturaleza es transformación", ¿en qué se transformará esta situación actual de crisis? y, sobre todo, ¿cómo nos transformaremos?

\section{Una conversación abierta}

Como decíamos al inicio, la propuesta del espacio Selvagem, ciclo de estudos sobre a vida es propiciar el diálogo de saberes. Precisamente los participantes de esta conversación implican saberes diferentes: uno expresa el saber científico, y su lugar clave de autoridad en la cultura moderna occidental; el otro expresa el saber indígena, históricamente desconocido e invisibilizado por aquella cultura. Sin embargo, el contenido y el tono del diálogo se desplazan de esos lugares; se muestra, por el contrario, una escucha atenta y respetuosa, una búsqueda por acercar miradas y propuestas e, incluso, una abierta interpelación de Ailton Krenak a la ciencia moderna por sus efectos sobre vidas humanas y no humanas.

Para continuar el acercamiento a esta propuesta se puede seguir el ciclo completo a través de su canal de YouTube (https://www.youtube.com/channel/ UCJFxuy0nRF3Z9YvBW7vljCA); también, a través de los cuadernos de lecturas disponibles online en el sitio de la Editorial Dantes (https://dantes.com. br) o en el sitio del ciclo (selvagemciclo.com.br), una plataforma desde la cual es posible acceder de manera gratuita a la publicación Cadernos Selvagem (ocho números que proporcionan la transcripción de conversaciones del ciclo), otros proyectos en curso (como la investigación y creación de un mapa con el significado de los nombres indígenas de lugares de la ciudad de San Pablo), ciclos de lecturas y abundantes materiales visuales. 
La conversación y los temas que involucra siguen abiertos, en debate. Por ejemplo, queda pensar en otras ficciones (como "la economía") y también reflexionar sobre una diversidad de propuestas que se vienen transitando a través del diálogo e intercambio de saberes (por caso, las relativas a la soberanía alimentaria, entre muchas otras).

\section{Hortensia Castro / sitacastro@yahoo com.ar, hcastro@filo.uba.ar}

Profesora de Geografía UBA, Magíster en Políticas Ambientales y Territoriales FFyL- UBA, Doctora en Geografía UBA. Como investigadora ha dirigido y dirige proyectos sobre mercantilización y patrimonialización de la naturaleza e integra el Grupo Cultura- Naturaleza-Territorio, ambos con sede en el Instituto de Geografía de la misma Facultad. Profesora Adjunta en el Departamento de Geografía de la Facultad de Filosofía y Letras (asignaturas Geografía Rural y Problemas Territoriales I) y en la Cátedra de Extensión y Sociología Rurales de la Facultad de Agronomía (asignatura Ambiente y Sociedad, Licenciatura en Ciencias Ambientales), UBA. Profesora Titular en la Maestría en Políticas Ambientales y Territoriales (FFyL, UBA) y en el Doctorado en Estudios Territoriales (Universidad de Caldas, Colombia). 